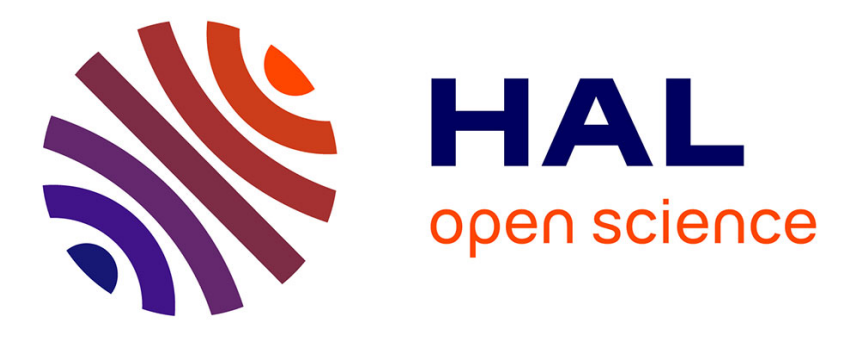

\title{
Urban and industrial land uses have a higher soil biological quality than expected from physicochemical quality
}

Sophie Joimel, Christophe Schwartz, Mickael Hedde, Sayuri Kiyota, Paul Henning Krogh, Johanne Nahmani, Guenola Peres, Alan Vergnes, Jérôme Cortet

\section{To cite this version:}

Sophie Joimel, Christophe Schwartz, Mickael Hedde, Sayuri Kiyota, Paul Henning Krogh, et al.. Urban and industrial land uses have a higher soil biological quality than expected from physicochemical quality. Science of the Total Environment, 2017, 584-585, pp.614-621. 10.1016/j.scitotenv.2017.01.086 . hal-01507698

\section{HAL Id: hal-01507698}

\section{https://hal-univ-rennes1.archives-ouvertes.fr/hal-01507698}

Submitted on 26 May 2020

HAL is a multi-disciplinary open access archive for the deposit and dissemination of scientific research documents, whether they are published or not. The documents may come from teaching and research institutions in France or abroad, or from public or private research centers.
L'archive ouverte pluridisciplinaire HAL, est destinée au dépôt et à la diffusion de documents scientifiques de niveau recherche, publiés ou non, émanant des établissements d'enseignement et de recherche français ou étrangers, des laboratoires publics ou privés.

\section{다(1)(2)}

Distributed under a Creative Commons Attribution - ShareAlikel 4.0 International 


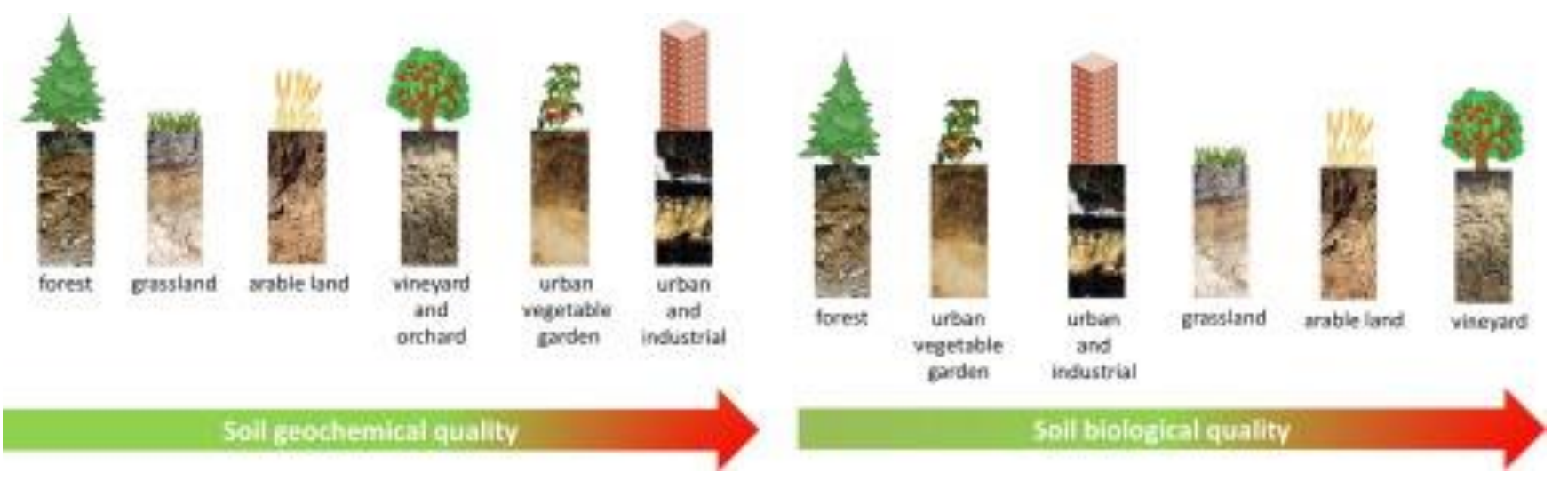

Sophie Joimel, Christophe Schwartz, Mickaël Hedde, Sayuri Kiyota, Paul Henning Krogh, Johanne Nahmani, Guénola Pérès, Alan Vergnes, Jérôme Cortet

Urban and industrial land uses have a higher soil biological quality than expected from physicochemical quality

Science of The Total Environment, Volumes 584-585, 2017, 614-621

http://dx.doi.org/10.1016/j.scitotenv.2017.01.086 